\title{
Hyperbaric Oxygen Therapy as an Adjunct to Surgical Treatment of Extensive Hidradenitis Suppurativa
}

\author{
E. Balik · T. Eren · T. Bulut $\cdot$ Y. Büyükuncu • \\ D. Bugra $\cdot$ S. Yamaner
}

Published online: 9 February 2010

(C) Société Internationale de Chirurgie 2010

We appreciate the comments by Uzun et al. [1]. In our series, we did not consider the option of hyperbaric oxygen therapy (HBOT) because we did not experience any serious wound complications. This was due to the meticulous wound care carried out in our clinic. We also did not experience any recurrences [2]. In cases of serious woundsite infections, however, HBOT may be an alternative treatment, although it should always be accompanied by surgery and intensive surgical wound care [1].

Apart from wound-site infections, this modality can be considered for the purpose of shortening the wound-healing period for patients whose wounds are left open for secondary intention. In our study, despite the 2-week mean healing period for the rotation flap group, the mean healing times of the patients who were treated with skin grafts and secondary intention were 8.0 and 12.2 weeks, respectively (almost 2 and 3 months, respectively) [2]. This prolonged healing period might have been avoided had the enhanced wound-healing effects of HBOT mentioned by Uzun et al. [1] been applied.

We can see that there is a lack of data in the literature concerning the use of HBOT as an adjunct to surgery in such cases and agree that the role of HBOT in hidradenitis suppurativa cases should be researched in a randomized controlled trial.

\section{References}

1. Uzun G, Özdemir Y, Mutluoğlu M et al (2009) Hyperbaric oxygen therapy as an adjunct to surgical treatment of extensive hidradenitis suppurativa. World J Surg. doi:10.1007/s00268-009-0326-6

2. Balik E, Eren T, Bulut T et al (2009) Surgical approach to extensive hidradenitis suppurativa in the perineal/perianal and gluteal regions. World J Surg 33:481-487
E. Balik (凹) · T. Eren · T. Bulut · Y. Büyükuncu · D. Bugra · S. Yamaner

Department of General Surgery, Istanbul Faculty of Medicine, University of Istanbul, Istanbul, Turkey

e-mail: ebalik@istanbul.edu.tr 